\title{
The Photocatalytic Activity of Cement in Reducing Air Pollutants
}

\author{
L. Chandrakanthamma. M. Jothilakshmi, K. S. Dhayachandhran, Rounak Goel
}

\begin{abstract}
Air pollution is the major concern in the recent years because of causing imbalance to the ecosystem and also increases global warming and climate change. This paper, tries to investigate the applicability of photo catalytic cement in removing the pollutants under partially controlled and simpler experimental conditions such that it mimics the ideal state of its use, that is the natural open environment where it always is susceptible to complex physical and chemical interactions. It also gives an overview of the concentrations of the contaminants reduced not limiting to NOx residues alone, by employing Ion Chromatography instead of NOx analyzers.
\end{abstract}

Keywords: Photo catalytic cement, Titanium dioxide, Air Pollution, Civil and Environmental Engineering.

\section{INTRODUCTION}

The oxidation of environmental pollutants is caused by the Redox reactions on the photo catalyst surface. The photo catalytic cement developed by the Italcementi group is on a rapid increase and is the focal point of all environmental research being carried out in this domain [4]. Through mobilizing dirt and stains, the photo-induced surface enhances the self-cleaning effect. It is done through the rainwater soaking between the adsorbed substance and the $\mathrm{TiO}_{2}$ surface.

Photo catalytic oxidation (PCO) has become a valid alternative in NOx remediation among all the other alternatives, which is highly amphiphilic in nature [6]. The pollution mitigation is mainly achieved by oxidation of nitrogen oxides to nitrites or nitrates. NOx represents the total concentration of nitric oxide (NO) and nitrogen dioxide $\left(\mathrm{NO}_{2}\right)$. They are essentially paints or cements containing photoactive $\mathrm{TiO}_{2}$ [1]. The advantage of $\mathrm{PCO}$ over other technologies is that it requires only light, atmospheric oxygen and water. This catalyst can be supported on conventional structures as the photo catalytic pavement blocks, filters, membranes etc., for indoor/outdoor air purifications.

\section{Principle behind photoactivity.}

\section{a. The Photocatalyst}

Titanium dioxide, also known as titanium. It is the naturally occurring oxide of titanium, chemical formula $\mathrm{TiO}_{2}$ When used as a pigment, it is called titanium white. $\mathrm{TiO}_{2}$ used in production of paving blocks[1].

Generally, it is sourced from the ilmenite ore, and has three forms rutile, anatase and brookite[5]. It has a wide range of applications, including paint, coatings, sunscreen and food colouring. The Anatase form is known to have the highest photocatalytic activity of all its types and hence was opted for the experiment[4].

\section{b. The Concept}

For Heterogeneous photocatalysis, a semiconductor photocatalyst in contact with a liquid or gas reaction medium is needed. The most popular semicoductor $\mathrm{TiO} 2$, is the first type of semiconductor material,due to its positive valence band edge that oxidizes water to oxygen [11].. Its excellent photocatalytic properties plays important role such as highly oxidizing, photogenerated holes that produce hydroxyl radicals, as well as photogenerated electrons that produce super oxides from dioxygen.

When $\mathrm{TiO}_{2}$ is exposed to energy, from photons, that exceeds its band gap energy, an electron is expelled from the valence band to the conduction band, leaving a hole behind [10] [11]. This process is initiated by energy from a UV light wavelength determined by the electromagnetic radiation which gives the chemical reactions and to improve the Air quality in highly polluted Areas [2].

\section{c. $\quad$ The Chemical Interactions}

The chemical interactions taking place on the activated surface can be understood from the following brief. In the presence of water, the oxidizing holes, $\mathrm{h}+$, and photogenerated electrons, e-, create hydroxyl radicals and super oxides respectively.

$$
\mathrm{OH}^{-}+\mathrm{h}^{+} \rightarrow \mathrm{OH}^{*}
$$$$
\mathrm{O}_{2}+\mathrm{e}^{-} \rightarrow \mathrm{O}_{2}^{-}
$$

The resulting hydroxyl radicals and super oxides are key for oxidation or reduction reactions allowing for degradation of pollutants in the oxidation of NOx to water soluble nitrites or nitrates in presence of Titanium dioxide as the catalyst.

$$
\begin{aligned}
& \mathrm{NO}+\mathrm{OH}^{*} \rightarrow \mathrm{NO}_{2}{ }^{-}+\mathrm{H}^{+} \\
& \mathrm{NO}_{2}+\mathrm{OH}^{*} \rightarrow \mathrm{NO}_{3}{ }^{-}+\mathrm{H}^{+}
\end{aligned}
$$

A pictorial representation is given in Fig.1 for clearer interpretation of the process.

Revised Manuscript Received on 14 August, 2019.

L.Chandrakanthamma, Assistant Professor, Dept. of Civil Engg., EaswariEngg College, Chennai-600089, Tamil Nadu, India. (Email: meetchandrakantha@gmail.com)

M.Jothilakshmi, Assistant Professor, Dept. of Civil Engg. , EaswariEngg College, Chennai-600089, Tamil Nadu India

K.S.Dhayachandhran, Assistant Professor, Dept. of Civil Engg. , EaswariEngg College, Chennai-600089, Tamil Nadu India

RounakGoel, UG Student, Department of Civil Engineering EaswariEngg College, Chennai-600089, Tamil Nadu India

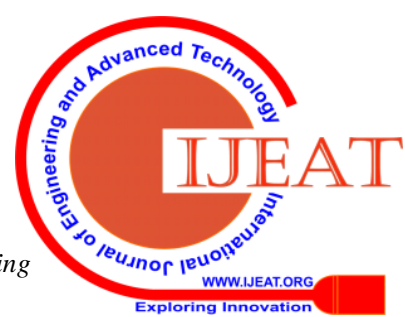


THE PHOTOCATALYTIC ACTIVITY OF CEMENT IN REDUCING AIR POLLUTANTS
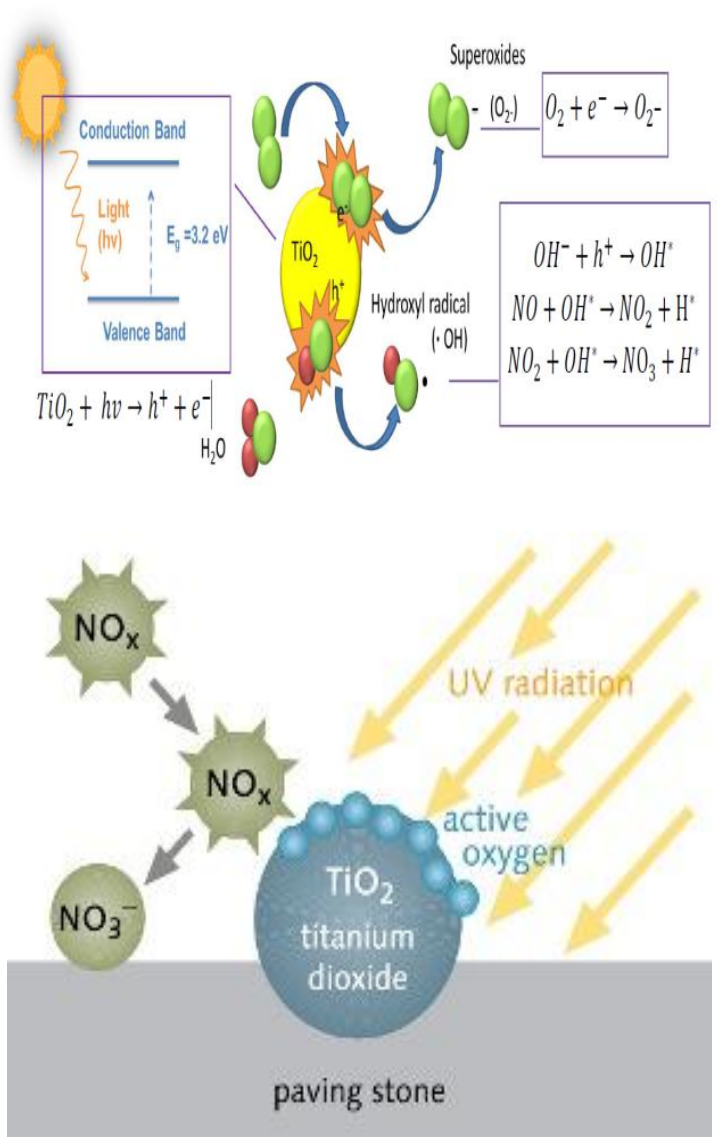

Fig.1 : Photo catalytic process

\section{EXPERIMENTAL DETAILS\& RESULTS}

\section{a. Materials}

The following materials with the mentioned properties were used in developing the cement slurry.

- CEMENT: White Ordinary Portland Cement (White OPC) was used here instead of grey OPC due to greater light scattering ability of the white cement and its aesthetic appeal.

- $\quad$ FINE AGGREGATES: Two more aggregates other than river sand were also used to study the enhancement in the photo activity due to their inclusion, fly ash and crushed glass aggregates were the aggregates used to replace sand. All the fines were made to pass through IS $2.36 \mathrm{~mm}$ sieve and only the portion passing through was used.

- WATER: Potable water was used for mixing the materials for preparing the slurry.

\section{b. Mix proportion}

This study focused on preparing cement mortar mixes with cement to aggregate ratios of 1:3, with aggregates finer than $2.36 \mathrm{~mm}$ in size. The sample preparation was restricted to a small number by carefully understanding the varies properties that influenced the photo activity (from literatures reviewed) thereby saving time, resources and focusing on more meaningful objectives within the stipulated time.

Table 1 defines the mix ratios of the samples prepared and studied under this project scheme.
TABLE I : MIX PROPORTIONS

\begin{tabular}{|l|l|l|l|l|l|l|}
\hline $\begin{array}{l}\text { Test } \\
\text { Sampl } \\
\text { e }\end{array}$ & $\begin{array}{l}\text { Cemen } \\
\text { t }\end{array}$ & $\begin{array}{l}\text { San } \\
\text { d }\end{array}$ & $\begin{array}{l}\text { Crushe } \\
\text { d Glass }\end{array}$ & $\begin{array}{l}\text { Fly } \\
\text { As } \\
\text { h }\end{array}$ & $\begin{array}{l}\text { TiO } \\
\mathbf{2}\end{array}$ & $\begin{array}{l}\text { Wate } \\
\text { r }\end{array}$ \\
\hline S1 & 1 & 3 & 0 & 0 & 0 & 0.4 \\
\hline S2 & 1 & 3 & 0 & 0 & 0.1 & 0.4 \\
\hline S3 & 1 & 2.5 & 0 & 0.5 & 0.1 & 0.4 \\
\hline S4 & 1 & 1 & 2 & 0 & 0.1 & 0.42 \\
\hline
\end{tabular}

c. Preparation of water samples for analysis of pollutants

A total of four samples were prepared, one with the conventional mix (S1) and the rest with varied combination of aggregates and photo catalyst (refer Table I). All surface layers were fabricated in moulds having internal dimensions $180 \times 120 \times 30 \mathrm{~mm}$. The wet mixed layers of each sample weighed about $1500 \mathrm{~g}$. All mixes were manually mixed and compacted. All the samples were cured for 3 days.

Then the cement samples were demoulded and subjected to conditions so as to simulate automobile exhaust emissions, for this a single cylinder diesel engine was incorporated. The engine was made to operate at full loading condition and each sample was exposed to the exhaust for about 20 minutes. Before exposing the samples the engine was made to run for about 15 minutes to attain a stabilized flow.

After this the samples were placed in an ultra violet (UV) irradiation chamber having dimensions $15 \times 12 \times 10$ inches

The samples upon being exposed to the UV radiations get activated and the catalytic chemical reactions are initiated.

The radiations are made to fall upon the samples for 20 minutes again, with radiations being made to stabilize for 15 minutes prior sample exposure

The samples then were washed clean with lukewarm distilled water in order to make sure all the impurities are well collected within those water samples which would

further be tested for the constituents of the reduced pollutants contained in them using Ion Chromatography.

Ion chromatography (IC) is a chromatography process which separates ions, polar molecules based on their affinity to the ion exchanger. There are two types of ion chromatography 1)anion-exchange 2) cation-exchange. In this paper, anion exchange chromatography is carried out. We focused on the NOx reduced compounds, nitrites and nitrates both of which being anions.Anion-exchange chromatography, when in the stationary phase is positively charged and negatively charged molecules are loaded to be attracted to it. 
TABLE II : CONSOLIDATED NITRITE AND NITRATE ION CONCENTRATIONS

\begin{tabular}{|l|l|l|}
\hline Test Sample & $\begin{array}{l}\text { Nitrite }\left(\mathbf{N O}_{2}{ }^{-}\right) \\
\text {ion } \\
\text { concentration } \\
(\mathbf{m g} / \mathbf{l})\end{array}$ & $\begin{array}{l}\text { Nitrate }\left(\mathbf{N O}_{\mathbf{3}}{ }^{-}\right) \\
\text {ion } \\
\text { concentration } \\
(\mathbf{m g} / \mathbf{l})\end{array}$ \\
\hline S1 & 0.70 & 0.78 \\
\hline S2 & 2.48 & 1.52 \\
\hline S3 & 3.60 & 0.90 \\
\hline S4 & $\mathbf{2 2 . 8 2}$ & $\mathbf{0 . 1 0}$ \\
\hline
\end{tabular}

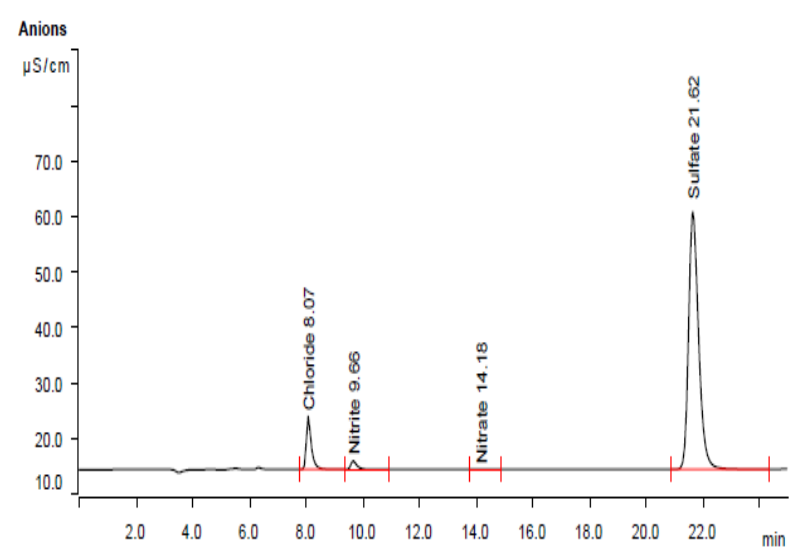

\begin{tabular}{|c|c|c|c|c|}
\hline \multirow[t]{2}{*}{ Component name } & Retention time & Height & Area & Concentratior \\
\hline & $\min$ & $\mu \mathrm{S} / \mathrm{cm}$ & $(\mu \mathrm{S} / \mathrm{cm}) \times \min$ & $\mathrm{mg} / \mathrm{h}$ \\
\hline Chloride & 8.072 & 9.549 & 1.9624 & 76.294 \\
\hline Nitrite & 9.655 & 1.528 & 0.3831 & 22.817 \\
\hline Nitrate & 14.177 & 0.003 & 0.0011 & 0.081 \\
\hline Sulfate & 21.623 & 46.302 & 18.9957 & 1034.982 \\
\hline
\end{tabular}

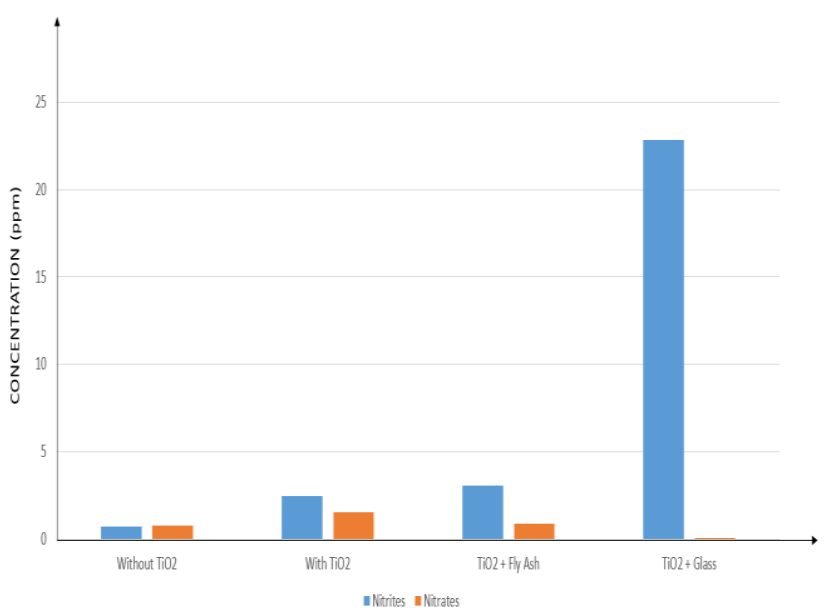

Fig 3. Graphical Representation of nitrite and nitrate ion concentrations

\section{CONCLUSIONS}

The photo catalytic behavior of $\mathrm{TiO} 2$ infused cement mortar layers was thus studied employing Ion Chromatography techniques in open uncontrolled conditions and the following conclusions were drawn.

- $\quad$ The use of photo catalytic cement as a pollutant reducing material is justified by significant occurrence of nitrite/nitrate ion concentrations or in other words the conversion of NOx into lesser harmful compounds.

- The photo catalytically active sample (S2) with $\mathrm{TiO} 2$ alone showed 3 times more NOx conversions (nitrites) in comparison to the conventional cement sample (S1).
- $\quad$ The sample with which consisted of fly ash (which was a partial replacement of sand) proved to be $20 \%$ more effective than sample (S2) in its performance.

The sample with glass aggregates was the best performing mix showing about 7 times more conversions than sample (S3) and an impressive 32 times greater conversion rate in comparison to the conventional sample (S1)

\section{REFERENCES}

1. C. S. Poon, et.al.,- NO removal efficiency of photocatalytic paving blocks prepared with recycled materials, International Journal of Construction and Building Materials',Volume 21,Issue8-2007- 17461753

2. M. M. Ballari, et.al.,- Experimental study of the NO and NO2 degradation by photocatalytically active concrete, International Journal of ' Catalysis Today',Volume 161,Issue1-2011- 175-180.

3. Jun Chen,et.al.,- Photocatalytic activity of titanium dioxide modified concrete materials - Influence of utilizing recycled glass cullets as aggregates, Volume 90,Issue11-3436-3442.

4. G. Hu“ sken,et.al.,-Experimental study of photocatalytic concrete products for air purification,International Journal of 'Building and Environment', 44, (2009) 2463-2474

5. A. Fujishima,et.al.,-TiO2 Photocatalysis: Fundamentals materials and Application, photocatalytic activity,1999-vol1,Issue1,1-21

6. R. Wang,. Et.al.,-Light-induced amphiphilic surfaces, Nature,International journal of science, vol. 31 431-432, 1997.

7. S. Marsili-Libelli - Simplified kinetics of tropospheric ozone , Ecol. Mod. 84 (1996) 233-244.

8. B.N. Shelimov, et.al.,- Enhancement effect of TiO2 dispersion over alumina on the photocatalytic removal of NOx admixtures from $\mathrm{O} 2$ N2 flow" J. Photochem. Photobiol. A: Chem. 195 (2008) 81-88.

9. S. Devahasdin, et.al., -TiO2 photocatalytic oxidation of nitric oxide: transient behavior and reaction kinetics, Journal of Photochem. Photobiol. A:Chem. Volume-156-Issue 1,2,3- 2003 ,Pages 161-170.

10. B.N. Shelimov, et.al.,- Enhancement effect of $\mathrm{TiO} 2$ dispersion over alumina on the photocatalytic removal of NOx admixtures from $\mathrm{O} 2$ N2 flow" J. Photochem. Photobiol. A: Chem. 195 (2008) 81-88.

11. B.N. Shelimov, et.al.,- Enhancement effect of $\mathrm{TiO} 2$ dispersion over alumina on the photocatalytic removal of NOx admixtures from $\mathrm{O} 2$ N2 flow" J. Photochem. Photobiol. A: Chem. 195 (2008) 81-88.

\section{PROFILE}

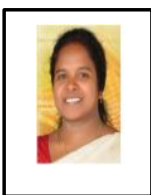

Mrs.L.Chandrakanthamma,Asst.Prof., Department of Civil Engineering,

Easwari Engineering College.

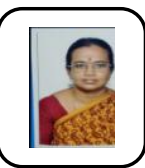

Mrs,M.JothiLakshmi,Asst.Prof.

Deaprtment of Civil Engineering, EaswariEngineering College.

Mr.K.S.Dhayachandhran,Asst.Prof,

Department of Civil Engineering,Easwari Engineering College 